\title{
Relation between diastolic left ventricular wall stress and strain in man
}

\author{
D. G. Gibson and D. J. Brown \\ From the Department of Cardiology, Brompton Hospital, London, and Computer Centre, Westminster Hospital, \\ London
}

Continuous measurements of left ventricular pressure were made by micromanometer and of dimension and posterior wall thickness by echocardiography in 23 patients with cardiomyopathy or valvular heart disease. From these, the stress-strain relation of a region of myocardium in the posterior wall was derived throughout diastole. This was complex, showing an early diastolic period of rapid change corresponding with the end of ventricular contraction, a middle period when wall stiffness was very low, and a late period when wall stiffness was finite and relatively constant. Stress-strain characteristics in this last period were related to cardiographic evidence of left ventricular hypertrophy: in its absence the average value of elastic modulus was $260 \mathrm{~g}$ $\mathrm{cm}^{-2}$, while in its presence it was $930 \mathrm{~g} \mathrm{~cm}^{-2}$. The stress-strain characteristics of left ventricular myocardium were dependent on the previous contraction and could be related to the pattern of filling throughout diastole.

The relation between left ventricular pressure and volume changes during diastole is complex, depending on cavity shape and size as well as on the properties of the left ventricular wall. Since changes in volume may result solely from altered ventricular geometry with no distension of the myocardium, pressure-volume relations cannot be taken as reflecting the stiffness of the wall itself. In the present study, therefore, we have attempted to dissociate the effects of changing cavity shape from those of wall stiffness in determining the pattern of left ventricular filling, and have assessed the properties of a localized area of myocardium using a method that makes only minor assumptions about left ventricular geometry. This has enabled us to make continuous measurements of the relation between wall stress and strain in this single region throughout diastole, and to define the effects of left ventricular hypertrophy upon it.

\footnotetext{
Subjects and methods

Measurement of stress

In describing the elastic properties of any substance, it is necessary to establish the relation between strain and stress. Stress is the force causing the change in shape divided by the cross-sectional area over which it acts and has both magnitude and direction. Strain is the proportional deformation which results from the applica-

Received 18 April 1974.
}

tion of a stress, expressed as the ratio of increase in length to initial (unstressed) length. Elasticity is the ratio of stress to strain, and is usually referred to as Young's modulus, with the dimensions $\mathrm{g} \mathrm{cm}^{-2}$. Since the relation between stress and strain need not be linear, an elastic modulus can be defined as the slope of the stress-length curve at a particular length. This modulus has the units $\mathrm{g} \mathrm{cm}^{-3}$ and represents the increase in stress needed to increase length by $\mathrm{I} \mathrm{cm}$, regardless of initial length.

These simple mechanical ideas can be applied to a region of left ventricular free wall studied by echocardiography, which is assumed to be part of an ellipsoid with finite wall thickness (Falsetti et al., 1970). The magnitude of the force within the wall depends on the left ventricular pressure and the dimensions of the cavity, and it has components directed both circumferentially and longitudinally. In the present study, only the circumferential component is considered, which is assumed to act around an annulus of myocardium whose endocardial surface is $\mathrm{I}$ cm across, and whose internal diameter is perpendicular to the long axis of the ellipsoid, and is given by the echocardiographic dimension. The contribution of inertial forces, caused by the outward movement of myocardium during diastole, to wall tension, has been shown to be negligible compared to the tension needed to support static equilibrium (Hefner et al., 1962; Tallarida, Rusy, and Loughnane, 1970) and is not considered. It is implicit in the geometry of the model that the left ventricle remains circular in the equatorial plane during diastole, and thus shear stresses may also be ignored. The radius of curvature of the myocardial segment studied is taken to be that at the 
mid-point of the wall. The major axis of the left ventricle is calculated from a linear function of echocardiographic dimension derived from estimates of major axis length at end-systole and end-diastole (Gibson, 1973). The defining equations for major axis length are:

$$
\begin{aligned}
& \mathrm{L}_{\mathrm{S}}=4.18+\mathrm{I} \cdot 14 \mathrm{M}_{\mathrm{S}} \\
& \mathrm{L}_{\mathrm{D}}=5.90+0.98 \mathrm{M}_{\mathrm{D}}
\end{aligned}
$$

where $L$ is the length of the major axis, $M$ the length of the echocardiographic dimension $(\mathrm{cm})$, and the suffixes $S$ and $D$ denote end-systolic and end-diastolic, respectively.

The length of the major axis corresponding to a minor axis length $M$ during diastole is calculated as:

$$
L=\frac{\left(L_{D}-L_{s}\right)}{M_{D}-M_{S}}\left(M-M_{S}\right)+L_{\mathbf{s}} \text {. }
$$

Wall thickness (W) is defined as the distance between endocardial and epicardial echoes at the posterior wall.

The average circumferential stress $(\sigma)$ across the wall at the equator is then:

$$
\sigma=\frac{P M}{4 W} \frac{\left(2 L^{2}-M^{2}\right)}{\left(\mathrm{L}^{2}+M W\right)} .
$$

When the ventricular pressure $P$ is expressed in $\mathrm{mmHg}$, and the lengths in cm, the stress, in $\mathrm{g} \mathrm{cm}^{-2}$ is then:

$$
\sigma=\frac{0.3399 \mathrm{PM}}{\mathrm{W}} \frac{\left(2 \mathrm{~L}^{2}-\mathrm{M}^{2}\right)}{\left(\mathrm{L}^{2}+\mathrm{MW}\right)}
$$

The elastic modulus of the myocardium is defined at mean equatorial circumference $\mathrm{C}$ as $\frac{\Delta \sigma}{\Delta \mathrm{C}} \mathrm{g} \mathrm{cm}^{-3}$. Mean equatorial circumference is the mid-wall circumference of an annulus of internal diameter $M$ and outer diameter $M+W$, and is equal to $\pi(M+W) \mathrm{cm}$. Since circumferential stress $\sigma$ is the average stress across the wall, midwall circumference is used to define the elastic modulus as a mean measure of stiffness from the endocardial layer to the epicardial layer. We have also normalized the elastic modulus to refer to unit length of circumference at end-diastole, since the increase in length caused by a given stress depends on initial length as well as on the elasticity of the material studied.

\section{Patients}

Studies were made on 23 patients with valvular heart disease or cardiomyopathy. They were a selected group only in so far as all of them required right and left heart catheterization for diagnostic purposes, and in all it was possible to record technically satisfactory echocardiograms of the left ventricular cavity and insert a No. 5 cardiac catheter through the aortic valve. Clinical and haemodynamic data are given in Table 1 . The nature and purpose of the investigation were explained to the patients, and their consent obtained. In no case did the investigation add more than 15 minutes to the procedure, and there were no complications. Using standard criteria (Oram, 197I), the patients were divided into two groups, according to whether the electrocardiogram showed evidence of left ventricular hypertrophy. Group A consisted of 8 patients whose electrocardiograms showed no evidence of left ventricular hypertrophy, and group B of I 5 patients whose electrocardiogram fulfilled at least one criterion.

\section{Cardiac catheterization}

The patients were studied fasting and were sedated with $200 \mathrm{mg}$ amylobarbitone given orally one hour before the start of the procedure. In 2 cases (I and 23) general anaesthesia was used. Left ventricular pressures were measured with a Millar micromanometer, mounted on a size 5 cardiac catheter, which was inserted through a right brachial arteriotomy, and were recorded photographically, with no electrical damping, using an SE 3012 recorder, operating at a paper speed of $100 \mathrm{~mm} / \mathrm{sec}$. An additional left ventricular pressure trace, amplified 5 to ro times, was also recorded to measure diastolic pressure more precisely. The micromanometer was checked against a mercury manometer immediately before insertion, and zero pressure was taken as atmospheric. A simultaneous electrocardiogram was also recorded.

\section{Echocardiographic measurements}

At the same time as left ventricular pressure was recorded, the left ventricular internal dimension was recorded on polaroid film, as previously described (Gibson and Brown, 1973) using an Ekoline 20 ultrasonoscope with a 2.25 MHz transducer and posterior wall thickness estimated by the method of Sjögren, Hytönen, and Frick (1970). In all cases clear, continuous echoes were recorded throughout the cardiac cycle, which were distinguished from those originating from the mitral valve apparatus. An identical electrocardiogram to that recorded with the pressure trace was superimposed on all echocardiograms, and during exposure, a I mV calibration signal was recorded on both, enabling the two to be correlated, and data from the same beat unequivocally identified on both records.

\section{Digitization}

Left ventricular echocardiograms were digitized as previously described (Gibson and Brown, 1973), using a DMAC digitizing table interfaced with an IBM 1800 computer, except that data points were generated for the epicardial surface of the posterior wall as well as its endocardial surface and the posterior of the two septal echoes. Approximately IOO points were defined on each of these three echoes in a single cardiac cycle, together with calibration signals representing $0.5 \mathrm{sec}, 2 \mathrm{~cm}$, and the onset of the $Q$ waves of the beat being studied and the succeeding beat. A similar procedure was used for the pressure record, and for the amplified diastolic trace, with calibration signals of $0.5 \mathrm{sec}, 50 \mathrm{mmHg}$, and the QQ interval as for the echocardiogram. The gain of the diastolic trace and the relative position of its zero were entered by teletypewriter. Both records were initially corrected for lack of rectilinearity on the digitizing table, and any beat in which estimates of $Q Q$ interval between pressure and echo traces differed by more than 3 per cent was rejected. Strings of 257 data points, 
TABLE I Clinical details

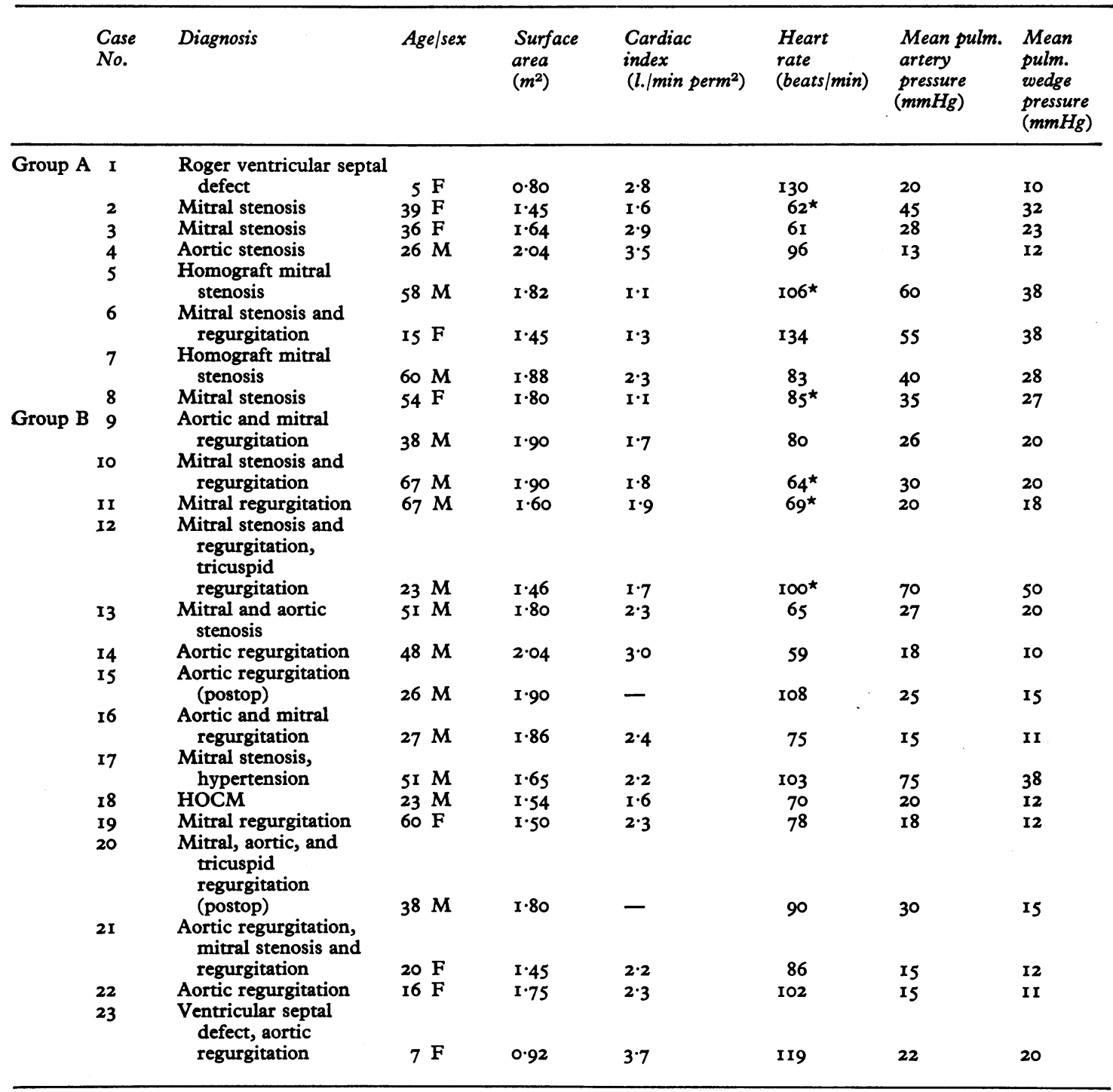

* Atrial fibrillation.

HOCM = hypertrophic obstructive cardiomyopathy.

equally spaced in time, were then generated for each of the echo and pressure traces: left ventricular wall thickness was derived as the difference between the coordinates representing its epicardial and endocardial surfaces, and cavity size as the difference between those representing posterior septal and posterior endocardial echoes. After smoothing with a three point moving average filter, this information was stored on tape and used for further calculations،

\section{Measurements}

From the digitized data, plots were made of left ventricular pressure, dimension, and wall thickness continuously throughout diastole, together with derived values of wall stress. Additional plots were made of the relation between wall stress and cavity circumference. Examples are given in Fig. $\mathrm{I}-4$.

The time of minimum dimension was taken as the 

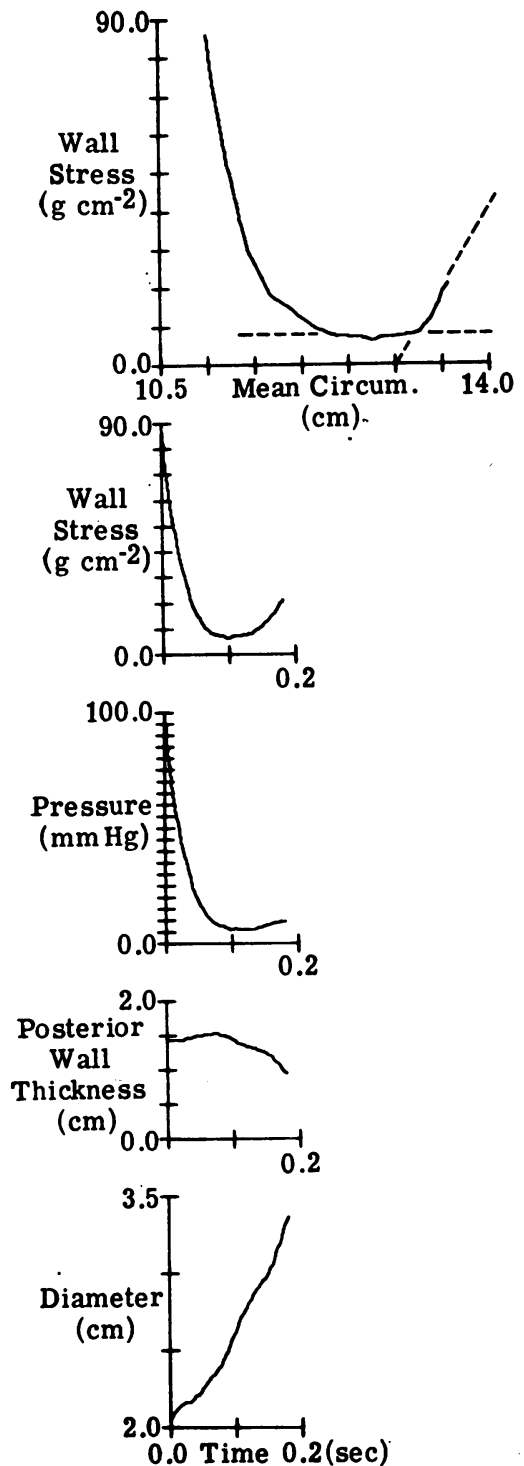

FIG. I Stress-strain relation and its determinants in a patient with a small ventricular septal defect (Case 1 ). The three lowest traces represent changes in left ventricular diameter, posterior wall thickness, and pressure, with time after the onset of diastole, and the trace above this, changes in wall stress. The top trace shows the relation between circumferential stress and mean ventricular circumference at mid-wall. Values of early and late diastolic elastic modulus are indicated by broken lines. 

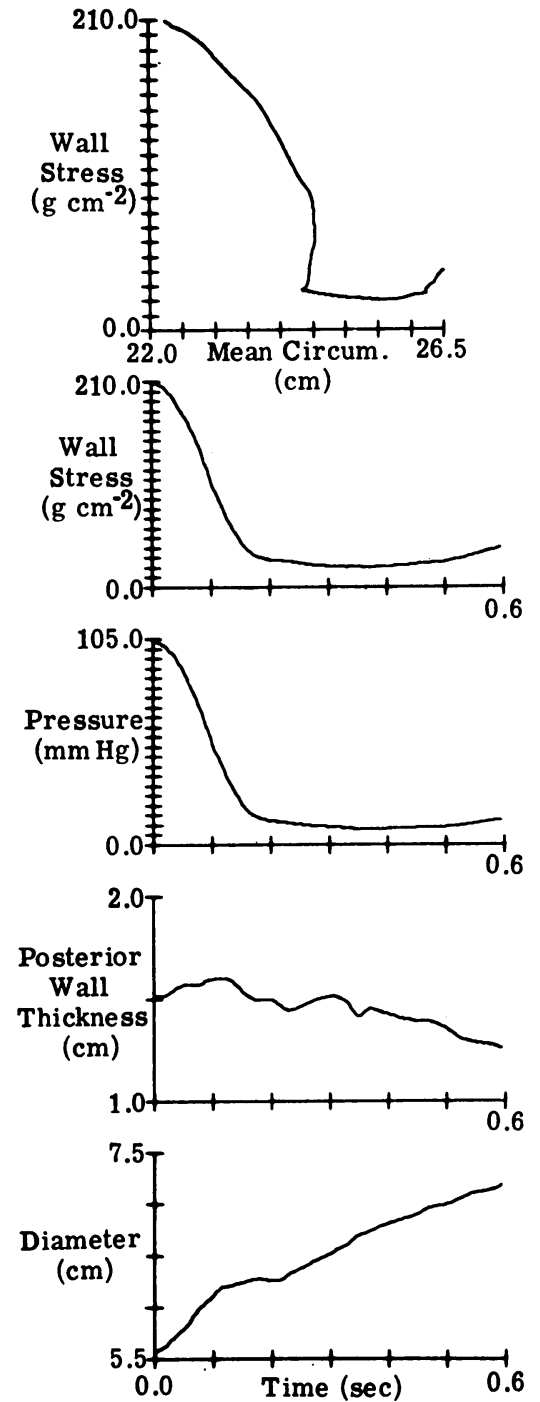

FIG. 3 Stress-strain relation and its determinants in a patient with aortic regurgitation and left ventricular disease (Case 14), showing prolongation of the relaxation phase of early diastole.

start of diastole, and measurements of left ventricular pressure and wall stress were made at this time, and also at end-diastole. In addition, the minimum values of both were recorded, together with the time interval after the start of diastole at which each occurred. These results are given in detail in Table 2.

Elastic modulus was measured from the graph of wall stress against circumference. The early diastolic value was taken as the slope of this graph between the time of minimum stress and that of the discontinuity when it was present. The late diastolic elastic modulus was the cor-
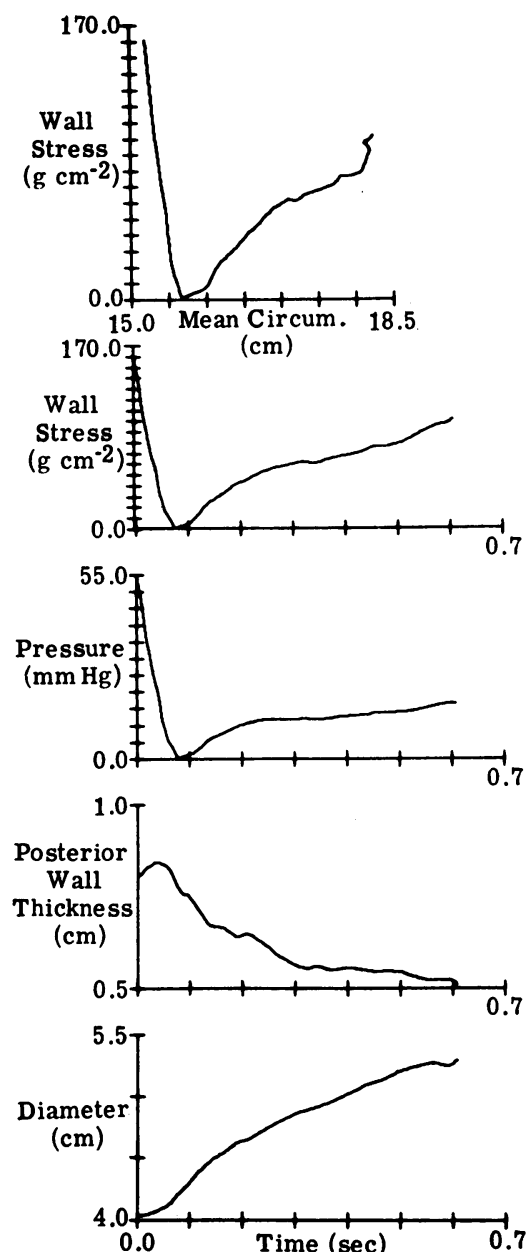

FIG. 4 Stress-strain relation and its determinants from a patient with pure mitral stenosis and a raised end-diastolic pressure (Case 2). For discussion see text.

responding slope from the time of the discontinuity until end-diastole, defined as the start of the inscription of the $Q$ wave of the succeeding beat. Normalized values of late diastolic modulus were also derived by multiplying by end-diastolic circumference, in order to give a measure of the elastic modulus of unit length of myocardium, and so to facilitate comparison between patients. In 5 patients, no discontinuity was present in the stresscircumference relation, and in these, mean values of the slope from the time of minimum stress until end-diastole are given. An example of such a patient is shown in 
TABLE 2 Left ventricular wall stress and its determinants

\begin{tabular}{|c|c|c|c|c|c|c|c|c|c|c|c|}
\hline & \multirow[t]{2}{*}{$\begin{array}{l}\text { Case } \\
\text { No. }\end{array}$} & \multicolumn{3}{|c|}{$\begin{array}{l}\text { Left ventricular pressure } \\
(\mathrm{mmHg})\end{array}$} & \multicolumn{2}{|c|}{$L V$ diameter $(\mathrm{cm})$} & \multicolumn{2}{|c|}{$\begin{array}{l}\text { Wall thickness } \\
(\mathrm{cm})\end{array}$} & \multicolumn{2}{|c|}{$\begin{array}{l}\text { Wall stress } \\
\left(\mathrm{g} \mathrm{cm}^{-2}\right)\end{array}$} & \multirow[b]{2}{*}{$\begin{array}{l}\text { End- } \\
\text { dia- } \\
\text { stolic }\end{array}$} \\
\hline & & Peak & $\begin{array}{l}\text { Min- } \\
\text { imum }\end{array}$ & $\begin{array}{l}\text { End- } \\
\text { dias- } \\
\text { stolic }\end{array}$ & $\begin{array}{l}\text { Min- } \\
\text { imum }\end{array}$ & $\begin{array}{l}\text { Max- } \\
\text { imum }\end{array}$ & $\begin{array}{l}\text { Min- } \\
\text { imum }\end{array}$ & $\begin{array}{l}\text { Max- } \\
\text { imum }\end{array}$ & Early & $\begin{array}{l}\text { Min- } \\
\text { imum }\end{array}$ & \\
\hline \multirow[t]{8}{*}{ Group A } & I & II 7 & 5 & 7 & $2 \cdot 0$ & 3.4 & 0.9 & $I \cdot 4$ & 80 & 8 & 20 \\
\hline & 2 & 140 & 0 & I5 & $4 \cdot I$ & $5 \cdot 2$ & 0.7 & 0.9 & 160 & 0 & IIO \\
\hline & 3 & II 6 & -4 & 2 & $4 \cdot 2$ & 5.5 & $I \cdot 0$ & $1 \cdot 3$ & 8 & -8 & 4 \\
\hline & 4 & 160 & IO & IO & $2 \cdot 0$ & $3 \cdot 4$ & $2 \cdot 0$ & $2 \cdot 3$ & 80 & I0 & 12 \\
\hline & 5 & IIO & 0 & 5 & $2 \cdot 4$ & $3 \cdot 2$ & $I \cdot O$ & $I \cdot 4$ & 70 & 0 & I0 \\
\hline & 6 & 120 & 25 & 25 & 3.9 & $5 \cdot 1$ & $I \cdot O$ & $1 \cdot 5$ & 140 & 60 & 70 \\
\hline & 7 & 137 & 7 & 9 & $2 \cdot 7$ & $5 \cdot 2$ & $\mathrm{I} \cdot 2$ & $2 \cdot 0$ & 30 & 7 & 17 \\
\hline & 8 & 120 & $-I$ & 3 & $2 \cdot 3$ & $3 \cdot 7$ & 0.9 & $1 \cdot 5$ & 30 & $-I$ & 7 \\
\hline Mean & & 127 & $5 \cdot 3$ & 9.5 & 3.0 & $4 \cdot 3$ & $I \cdot I$ & $1 \cdot 5$ & 75 & 9.5 & 31 \\
\hline SD & & 17 & $9 \cdot 2$ & $7 \cdot 5$ & 0.95 & 0.99 & 0.39 & 0.44 & 54 & 21 & 38 \\
\hline \multirow[t]{15}{*}{ Group B } & 9 & I IO & 0 & 32 & 6.9 & $8 \cdot 6$ & $I \cdot 2$ & $\mathrm{I} \cdot 4$ & 250 & 0 & IIO \\
\hline & 10 & 150 & -5 & I & $4 \cdot 2$ & $5 \cdot 7$ & 0.7 & 0.9 & 75 & -30 & 2 \\
\hline & I I & 147 & 9 & 18 & 3.8 & $5 \cdot 8$ & 0.7 & $I \cdot 4$ & 140 & 30 & 80 \\
\hline & 12 & 115 & -2 & 15 & 3.6 & $5 \cdot 5$ & 0.7 & 0.9 & 140 & -5 & 120 \\
\hline & 13 & 160 & 3 & 12 & 2.9 & $4 \cdot 6$ & 0.9 & $I \cdot 5$ & 100 & 3 & 35 \\
\hline & 14 & IIO & 6 & 12 & $5 \cdot 6$ & $7 \cdot 2$ & 0.8 & $1 \cdot 6$ & 210 & 10 & 43 \\
\hline & 15 & 127 & 2 & 8 & $5 \cdot 0$ & 5.5 & $I \cdot 2$ & $1 \cdot 5$ & 130 & 3 & 15 \\
\hline & 16 & 150 & 0 & 7 & 5.0 & 6.6 & 0.8 & I $\cdot 4$ & 170 & 0 & 15 \\
\hline & 17 & 210 & 2 & 4 & $5 \cdot 3$ & $5 \cdot 8$ & $I \cdot 3$ & $1 \cdot 5$ & 135 & 5 & II \\
\hline & 18 & 120 & $-I$ & 10 & $I \cdot 6$ & $3 \cdot 2$ & $I \cdot 2$ & $2 \cdot 0$ & 60 & $-I$ & 20 \\
\hline & 19 & 128 & -3 & 8 & $5 \cdot 3$ & 6.8 & $I \cdot 2$ & $2 \cdot 0$ & 140 & 0 & 25 \\
\hline & 20 & 103 & 3 & 8 & $2 \cdot 7$ & $4 \cdot 3$ & $1 \cdot 6$ & 2.5 & 40 & 2 & 10 \\
\hline & $2 I$ & 140 & -2 & 30 & $4 \cdot 2$ & 6.0 & 0.7 & $1 \cdot 3$ & 90 & -2 & 160 \\
\hline & 22 & 162 & -3 & 22 & $2 \cdot 3$ & $3 \cdot 6$ & $I \cdot 2$ & $\mathrm{I} \cdot 5$ & 60 & 30 & 80 \\
\hline & 23 & 150 & 10 & 30 & $4 \cdot 3$ & 5.8 & 0.7 & I. 4 & 170 & 15 & 75 \\
\hline Mean & & 138 & $I \cdot 3$ & 14.5 & $4 \cdot 2$ & $5 \cdot 7$ & $1 \cdot 0$ & $I \cdot 5$ & 127 & 4 & 53 \\
\hline SD & & 27 & $4 \cdot 4$ & 9.9 & I.4 & $1 \cdot 4$ & 0.29 & 0.41 & 60 & $14 \cdot 3$ & 48 \\
\hline $\mathbf{P}<$ & & NS & NS & NS & 0.05 & 0.05 & NS & NS & 0.05 & NS & NS \\
\hline
\end{tabular}

Fig. 4. The timing of the discontinuity was measured from a separate plot of circumference against time. These results are given in detail in Table 3.

\section{Critique of methods}

Echocardiographic The echocardiographic method of measuring the thickness of the posterior wall of the left ventricle was originally validated against angiograms by Sjögren et al. (1970). We have extrapolated these results to the remainder of the cardiac cycle, and our observations agree closely with continuous measurements of free wall thickness derived from cineangiograms made by Eber et al. (1969), and Falsetti et al. (1970). Correlation between angiographic minor axis and echocardiographic dimension has been confirmed in a previous study (Gibson, 1973) in which identical methods were used. The frequency response of the echocardiograph itself was measured directly using a step change in the target surface, and was found to be linear to 500 $\mathrm{Hz}$, while the digitizing and smoothing system showed 5 per cent attenuation at Io $\mathrm{Hz}$. The use of polaroid film to record echocardiograms has certain potential errors. Distortion of the field by the camera was found to be negligible in the depth axis and to have a maximum value of $I$ per cent in the time axis at the periphery of the field, and was, therefore, disregarded. A systematic error in the frequency of the time marker was corrected for throughout. An additional variation of \pm 2 per cent in the velocity of the time base at the sweep speed used over the extremes of the field was minimized by taking calibration points exposed at the same time as the beat being studied, so that this error was reduced to less than 0.5 per cent. The resolution of the echocardiograph working at $2.25 \mathrm{mHz}$, however, imposes a greater constraint on the precision with which the position of echoes can be measured, so that these residual errors were considered negligible. As an additional check, any beat in which estimates of QQ interval from pressure and echocardiogram differed by more than 3 per cent was rejected.

Measurement of pressure The frequency response of the Millar manometer was checked using the 'pop' method, and a resonant frequency of $1000 \mathrm{~Hz}$ was observed. Since it has previously been shown (Millar and Baker, 1973) that the resonant frequency of the 
TABLE 3 Left ventricular elastic modulus

\begin{tabular}{|c|c|c|c|c|c|c|c|}
\hline & \multirow[t]{2}{*}{ No. } & \multicolumn{3}{|c|}{ Elastic modulus } & \multirow{2}{*}{$\begin{array}{l}\text { Circumference } \\
\text { at discontinuity } \\
(\mathrm{cm}) \\
(\mathrm{cm})\end{array}$} & \multicolumn{2}{|l|}{ Time to } \\
\hline & & $\begin{array}{l}\text { Early } \\
\left(\mathrm{g} \mathrm{cm}^{-3}\right)\end{array}$ & $\begin{array}{l}\text { Late } \\
\left(\mathrm{g} \mathrm{cm}^{-3}\right)\end{array}$ & $\begin{array}{l}\text { Late } \\
\left(\mathrm{g} \mathrm{cm}^{-2}\right)\end{array}$ & & $\begin{array}{l}\text { Minimum } \\
\text { tension } \\
(\mathrm{sec})\end{array}$ & $\begin{array}{l}\text { Discontinuity } \\
(\mathrm{sec})\end{array}$ \\
\hline \multirow[t]{8}{*}{ Group A } & I & 0 & 40 & 540 & 13.3 & 0.12 & 0.14 \\
\hline & 2 & - & 50 & 830 & - & 0.09 & - \\
\hline & 3 & 0 & $6 \cdot 2$ & II & 18.9 & 0.05 & 0.18 \\
\hline & 4 & 0 & 2 & 32 & 16.0 & 0.08 & 0.12 \\
\hline & 5 & -3 & 14 & 180 & 13.5 & 0.15 & 0.20 \\
\hline & 6 & 0 & 12 & 230 & 19.0 & 0.11 & $0.1 I$ \\
\hline & 7 & - & 4 & 74 & - & 0.10 & - \\
\hline & 8 & 0 & 4.5 & 60 & 13.3 & 0.09 & 0.15 \\
\hline Mean & & -0.5 & 17 & 260 & 15.7 & 0.10 & 0.15 \\
\hline SD & & $I \cdot 2$ & $18 \cdot 2$ & 280 & $2 \cdot 7$ & 0.03 & 0.03 \\
\hline \multirow[t]{15}{*}{ Group B } & 9 & 0 & 48 & 1400 & $29 \cdot 7$ & 0.15 & 0.22 \\
\hline & IO & - & 18 & 320 & - & 0.05 & - \\
\hline & II & 0 & 25 & 470 & 18.5 & 0.15 & 0.15 \\
\hline & 12 & 0 & 35 & 580 & 16.8 & 0.14 & 0.18 \\
\hline & 13 & 0 & 25 & 440 & 16.5 & 0.07 & 0.22 \\
\hline & 14 & 0 & 40 & 1050 & 26.0 & 0.16 & 0.45 \\
\hline & 15 & 0 & 15 & 310 & $2 I \cdot 0$ & 0.08 & 0.11 \\
\hline & 16 & 0 & 30 & 670 & 22.5 & 0.12 & 0.16 \\
\hline & 17 & I & 60 & 1350 & $22 \cdot I$ & 0.12 & 0.13 \\
\hline & 18 & 0 & 130 & 1600 & 12.6 & 0.10 & 0.22 \\
\hline & 19 & 10 & 80 & 2060 & 25.9 & 0.12 & 0.32 \\
\hline & 20 & 0 & 25 & 450 & $18 \cdot 2$ & 0.10 & 0.20 \\
\hline & 21 & - & 42 & 870 & - & 0.11 & - \\
\hline & 22 & - & 50 & 660 & - & 0.10 & - \\
\hline & 23 & 15 & 85 & 1700 & 20.0 & 0.13 & 0.13 \\
\hline Mean & & $2 \cdot 2$ & 47 & 930 & 20.8 & 0.1 I & $0.2 \mathrm{I}$ \\
\hline SD & & $5 \cdot 7$ & 30 & 560 & $4 \cdot 8$ & 0.03 & 0.10 \\
\hline $\mathbf{P}<$ & & NS & 0.01 & 0.001 & 0.01 & NS & 0.05 \\
\hline
\end{tabular}

transducer itself is very much higher than this, the observed measurements probably relate to the apparatus used rather than to the transducer itself. The pressure gradient across the ventricular wall was assumed to be identical with the ventricular pressure, though it may have been greater than that since intrathoracic pressure has been shown to be 2 to $3 \mathrm{mmHg}$ subatmospheric. No correction was made for this and, though errors of this magnitude will alter calculated wall stress, they will have little effect on the stress-strain relation. The possibility of an additional dynamic component of pressure caused by dissipation of kinetic energy by a moving column of blood on a transducer almost perpendicular to the direction of flow was also considered, but quantification in the light of known rates of ventricular filling indicated that it was small enough to be disregarded.

\section{Assumptions in calculation of wall stress}

Geometrical It was assumed in the calculation of wall stress that the two elements studied lay on the equatorial region of a thick-walled ellipsoid. This does not imply that the left ventricular cavity was, in fact, this shape, since, given a uniform circumferential distribution of stress, the position of the remainder of the myocardium need not be specified. Since a significant echo only arises from surfaces perpendicular to the ultrasound beam, it is likely that the left ventricular dimension represents a diameter rather than a chord of the region studied. The use of half this diameter to represent the radius of curvature of the endocardial surface of the posterior wall element requires that the cross-section is circular, which is supported by the similarity of the anteroposterior and lateral minor axes in magnitude (Dodge et al., 1966). Derivation of circumferential stress also requires knowledge of the long axis of the ellipsoid, and rather than assume a constant relation between major and minor axes, we have allowed for changing cavity shape with increasing size by using a linear relation between echocardiographic dimension and major axis derived from a previous study (Gibson, 1973). Though this is less satisfactory than direct measurement, the effects of errors of long axis estimation on calculated values of circumferential stress are small (Fig. 5).

Anatomical The present method assumes that the left ventricular wall is homogeneous, whereas it contains endocardial, myocardial, and pericardial elements, and the myocardium itself is anisotropic and composed of layers of fibres disposed in a manner which we were not able to determine in our patients. The results thus represent mean forces which were not related in any 


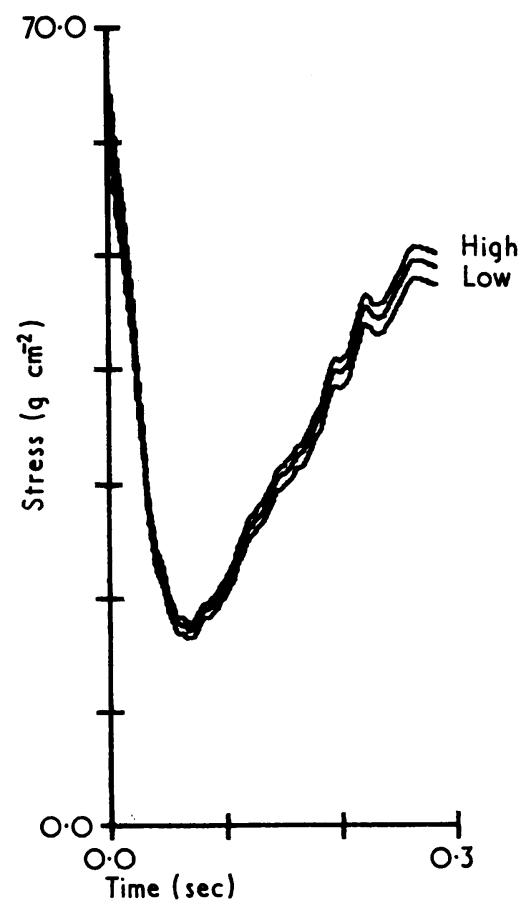

FI G. 5 Effect of errors in estimating long axis on calculation of circumferential stress (data from Case 2). The middle curve represents stress calculated using mean values predicted from echocardiographic dimension, and the upper and lower curves represent values of stress derived from the corresponding 95 per cent confidence limits of the regression line used. The differences are small.

recognizable way to structural elements within the wall. This fact is of less importance in diastole where the passive properties of the ventricle are being studied than in systole where stress is developed by fibre shortening. We have, therefore, expressed the results in terms of actual stress rather than fibre corrected stress, as suggested by Falsetti et al. (1970).

\section{Results}

\section{I) Composition of the two groups}

There were no significant differences between the two groups with respect to age, sex, rhythm, heart rate, cardiac index, or right heart pressures (Table I).

\section{2) Left ventricular pressure}

The mean value of peak left ventricular systolic pressure was the same in the two groups, as was the minimum diastolic pressure. In 8 patients, 2 in group A and 6 in group B, early diastolic pressures negative to atmospheric were recorded. Though the mean end-diastolic pressure was higher in group B, this difference was not significant, since in 2 patients in group A (Cases 2 and 6 ) it was raised above normal. In Case 6 , this was associated with tachycardia (134/min), while as in Case 2 (discussed in more detail later) the cause was not apparent.

\section{3) Left ventricular dimension}

Mean left ventricular dimension increased from $3.0 \mathrm{~cm}$ at end-systole to $4.3 \mathrm{~cm}$ at end-diastole in group A, while the corresponding figures in group $B$ were 4.2 and $5.7 \mathrm{~cm}$. Differences between mean values for the two groups were statistically significant at the 5 per cent level at end-systole and enddiastole, reflecting a greater cavity size in patients with cardiographic evidence of left ventricular hypertrophy.

\section{4) Posterior wall thickness}

Mean posterior wall thickness dropped from $\mathrm{r} \cdot 5 \mathrm{~cm}$ at end-systole to $\mathrm{I} \cdot \mathrm{I} \mathrm{cm}$ at end-diastole in group $\mathrm{A}$, a figure within the previously reported normal range (Sjögren et al., 1970; Troy, Pombo, and Rackley, 1972). In Case 4, wall thickness was clearly increased at $2 \mathrm{~cm}$, though this patient with congenital aortic stenosis had no cardiographic evidence of left ventricular hypertrophy. The corresponding figures in group $B$ were 1.5 and $1.0 \mathrm{~cm}$, which were not significantly different, though the larger cavity size in this group suggests that ventricular muscle mass was increased.

\section{5) Wall stress}

In group A, wall stress had a mean value of 75 $\mathrm{g} \mathrm{cm}^{-2}$ at the onset of outward wall movement, which rapidly dropped to a mean minimum value of $9.5 \mathrm{~g} \mathrm{~cm}^{-2}$ in mid-diastole, rising to $31 \mathrm{~g} \mathrm{~cm}^{-2}$ at end-diastole. This value is higher than that previously reported in patients without left ventricular hypertrophy (Falsetti et al., 1970) and reflects the high levels in Cases 2 and 6 in whom end-diastolic pressure was high. In those cases with a normal enddiastolic pressure, the mean value of end-diastolic wall stress was $10 \mathrm{~g} \mathrm{~cm}^{-2}$. In group $\mathrm{B}$, early diastolic wall stress had a mean value of $127 \mathrm{~g} \mathrm{~cm}^{-2}$.at early diastole, dropping to a minimum value of $4 \mathrm{~g} \mathrm{~cm}^{-2}$ and increasing to $53 \mathrm{~g} \mathrm{~cm}^{-2}$ at enddiastole. Only the first of these figures was significantly different from the corresponding value in group A.

6) Stress-strain relation Typical diastolic stress-strain relations are shown in Fig. I to 4. The early period of increasing dimension lasted approximately $0.1 \mathrm{sec}$ and appeared to be associated with the end of ventricular relaxation, so that no attempt was 
made to calculate a modulus of elasticity at this time. In the majority of patients in both groups, inspection of the curves revealed a second discontinuity later in diastole, which was followed by an increase in the change of stress per unit increase in circumference. This discontinuity was apparent in 18 of the 23 patients, and occurred at a mean value of mid-wall circumference of $15.1 \mathrm{~cm}$ in group A and $20.8 \mathrm{~cm}$ in group $B$, these figures representing 93 and 96 per cent of the end-diastolic circumference, respectively. Its timing in the two groups was different, being $0.15 \mathrm{sec}$ after the start of outward wall movement in A and $0.21 \mathrm{sec}$ in B. Values of elastic modulus were calculated for the periods of diastole before and after the discontinuity. In both groups of patients, the elastic modulus in early diastole was not significantly different from zero, the ellipsoidal model used predicting no measurable stiffness at this phase of the cardiac cycle. In late diastole, the mean elastic modulus was $\mathrm{I}_{7}$ $\mathrm{g} \mathrm{cm}_{\mathrm{f}}^{-3}$ in group $A$ and $47 \mathrm{~g} \mathrm{~cm}^{-3}$ in group $B$, the difference being significant at the I per cent level. When the elastic modulus was expressed in terms of unit length of circumference at end-diastole (i.e. as a Young's modulus), the corresponding values were $260 \mathrm{~g} \mathrm{~cm}^{-2}$ in group $A$ and $930 \mathrm{~g} \mathrm{~cm}^{-2}$ in group $B$, the difference between the two being statistically significant at the 0.1 per cent level. The results for one patient in group A (Case 2) with high values for elastic modulus are shown in Fig. 4. They show a steady rise in left ventricular pressure and wall stress throughout diastole as the circumference increased without the usual discontinuity. This patient had pure mitral stenosis, and the high end-diastolic pressure could not be explained clinically. It did not appear to reflect the presence of left ventricular disease, since peak rate of rise of left ventricular pressure was $1800 \mathrm{mmHg} / \mathrm{sec}$ though ventriculography showed a reduced ejection fraction $(0.45)$. It is possible, therefore, that left ventricular filling was restricted by rheumatic involvement of the mitral subvalve apparatus, though we have no direct evidence of this.

\section{Discussion}

In the present study, echocardiography was used to measure left ventricular dimension and wall thickness throughout diastole, in a single region of the posterior wall immediately below the mitral valve. When this information was combined with simultaneous cavity pressure measured with a micromanometer, it was possible to calculate values for mean circumferential wall stress and to document the way in which it varied with increasing circumference in the period of ventricular filling. No attempt was made to calculate ventricular volume from a single dimension, and the only significant geometrical assumption made was that the ventricular cavity was approximately circular at the site at which measurements were made. The results cannot necessarily be extrapolated to other regions of the left ventricle, particularly to the interventricular septum or papillary muscles. In addition, they bear no clear relation to the pressure-volume curve, which could only be predicted from them with knowledge of local variation in cavity shape, dimension, wall thickness, and fibre orientation, of the properties and pressure gradient across the septum, and of any additional effects of the mitral subvalve apparatus.

Stress-strain relations derived in the present study also differ significantly from those between pressure and dimension, in that calculated values of stress depend on the cross-sectional area over which forces act, and so are also determined by wall thickness. Since wall thickness may change by up to 60 per cent during diastole, and since this change does not occur uniformly with time but most rapidly in the early phase of filling, its consideration must modify conclusions about the behaviour of wall stress. Since the purpose of the present study was to investigate the mechanical properties of the left ventricular wall, the results have been presented in terms of stress and strain rather than pressure, diameter, and wall thickness. Clearly the results have the assumptions previously discussed implicit in their derivation, but the same applies to the measurement of stress in any other physical situation.

The difference in form between pressure-dimension and stress-strain relations from the same patient is illustrated in Fig. 6. The pressure-dimension relation is a smooth curve, demonstrating a progressive rise in pressure as dimension increases during the filling period. When wall thickness is taken into account, however, the form of the curve changes, with an alteration in slope appearing in mid-diastole, indicating that the relation between wall stress and strain is not a simple one. Taking the start of diastole as the time of minimum dimension, initial outward movement of the wall occurred in most patients as the ventricular pressure was still dropping after the previous systole. During this period, the ventricular wall was changing from the contracted to the relaxed state, so that no useful index of distensibility could be calculated. This initial period was followed by one in which wall stiffness was very low, or even zero, while late in diastole, corresponding to the increase in slope, wall stress rose in a linear manner with circumference, indicating that wall stiffness now had a finite value. In the majority of patients, the transition between 


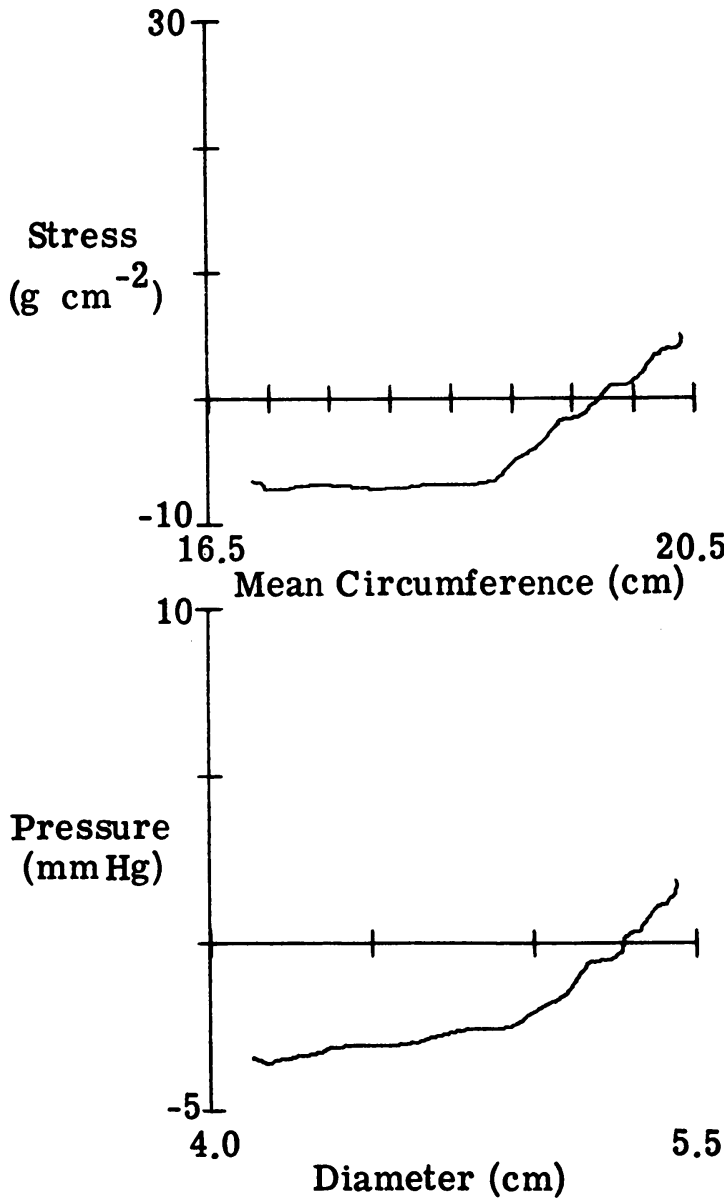

FIG. 6 Pressure-dimension and stress-strain relations from Case 3. The lower trace shows the diastolic pressure-dimension relation, which is a smooth curve, the discontinuity present in the stress-strain relation (upper trace) not being apparent.

these last two types of behaviour was abrupt, indicating that it would not have been possible to fit any simple continuous mathematical function, such as an exponential, to the observed results.

Diastolic stress-strain relations in the beating heart may differ from those in an arrested specimen in a number of ways. The most obvious was in early diastole, when the onset of outward wall movement occurred when pressure was still falling after the previous contraction. This was usually at a pressure greater than the ' $v$ ' wave of the left atrial trace, suggesting that this early period included isovolumic relaxation as well as the early phase of ventricular filling. In some patients, its onset was delayed until left ventricular pressure had reached its minimum value (Fig. 2), while in others, particularly those with left ventricular disease, outward wall movement started at very high pressures (Fig. 3), probably reflecting incoordinate ventricular contraction rather than filling (Gibson and Brown, 1974). This may explain the greater duration of this initial phase in patients with left ventricular hypertrophy (0.2I sec) compared to those without $(0.15 \mathrm{sec})$, though it was during this phase of filling in both groups of patients that the greatest rates of wall movement have been observed (Gibson and Brown, 1973). Our results do not allow us to determine whether ventricular filling at this time was passive, or whether stored energy from the previous contraction led to the development of diastolic suction. Evidence for such forces was reviewed by Brecher (1958), who reported negative diastolic pressure in open chest preparations, and, more recently, their presence in conscious dogs has been reported by Horwitz and Bishop (1972). In the present study, we recorded early diastolic pressures that were negative to atmospheric, though lack of knowledge about intrathoracic pressures makes their interpretation difficult, so that we were not able to confirm or exclude elastic recoil as a factor contributing to early diastolic filling in our patients.

The presence of very low myocardial stiffness in mid-diastole may also be directly related to the preceding contraction. It might have reflected distortion of ventricular geometry at end-systole, so that inflow of blood in the early filling phase was accommodated by changing cavity shape rather than by distension of the wall of the ventricle. If such a mechanism affected the region of myocardium studied, it would be associated with inequality of the anteroposterior and lateral minor axes of the ventricle at end-systole, for which there is no angiographic evidence. Alternatively, it is explicable on the basis of in vitro studies of isolated cardiac muscle. Gay and Johnson (1967) noted that when strands of myocardium from rabbit right ventricle were extended so as just to be taut, the muscle fibres composing them were slack and severely buckled. Only when the length of the strand was increased by 40 to 60 per cent did they become straightened and aligned along its long axis. These findings were extended by Grimm et al. (1970) who determined length-tension curves for isolated rat left ventricular papillary muscle. Active tension could be developed from 70 to 100 per cent optimum length, while passive tension was present only above 85 per cent; below this length, the muscle became slack with no resting tension. If these findings are relevant to man, enough shortening must have occurred at end-systole to bring the muscle into the slack region when it relaxed. This mechanism can 
be checked quantitatively, since under physiological conditions, sarcomeres are at 92 to 95 per cent of their optimal length just before the onset of systole. If the mechanism that we have suggested here is the basis of the diastolic stress-strain curve, it would be anticipated that the change from very low to finite stiffness would occur at a circumferential length approximately 8 per cent below end-diastolic, in close agreement with the observed findings. This reasoning can clearly be criticized in that it extrapolates from animals to man and from papillary muscle to free wall myocardium. In addition, it assumes that fibre orientation does not change during the cardiac cycle, and that end-diastolic fibre length was similar in our patients to normal animals. Nevertheless, the agreement between the observed results and those predicted provides indirect evidence for the mechanism proposed.

Rapid ventricular filling might also have caused stress-strain relations to depart from those observed in the static situation by the development of inertial and viscous forces. Inertial forces result from outward acceleration of the wall and lead to cavity pressure measurements being lower than would be recorded in static equilibrium. The maximum outward acceleration we have observed in man is $0.25 \mathrm{G}$ (Gibson and Brown, 1973), suggesting that these forces are negligible in the present connexion, a conclusion in line with that of Tallarida et al. (1970) in dogs. Viscous forces are proportional to the rate of lengthening of myocardium and result in wall stiffness being greater at the same cavity dimension than in the static situation. They would be expected to be most obvious, therefore, during early diastole and atrial systole, the two periods when ventricular filling is most rapid, so that an increase in wall stiffness in either of these two phases of diastole might be taken as evidence of their presence. Review of our data makes it unlikely that they are of great significance. During early diastole, the time of peak left ventricular filling rates (Gibson and Brown, 1973), stiffness was falling rapidly as the muscle relaxed. Though stiffness was increased in late diastole, this effect also occurred in patients in atrial fibrillation in whom atrial systole was clearly not a factor. In addition, the same characteristic stressstrain relation was seen in patients with mitral stenosis in whom ventricular filling occurred at a slower and more uniform rate throughout diastole. We conclude, therefore, that a discontinuous stressstrain relation did not result from the pattern of ventricular inflow, but that an increase in stiffness in late diastole reflected the intrinsic properties of the myocardium rather than the presence of viscous or inertial forces.

Although the form of the stress-strain relation differs from that between pressure and dimension, our results are directly comparable to those of Horwitz and Bishop (1972) in the dog. These workers defined three phases of the diastolic filling curve, an early period of elastic recoil, often with negative intraventricular pressure, a transient middiastolic period of decreasing pressure and increasing dimension, and a late period of increasing pressure caused by opposition of the ventricular wall. Though the division between the first two of these phases was not always clear, their published traces indicate a comparable abrupt onset to the third phase rather than a single exponential relation holding throughout diastole. In contrast to these results, Noble et al. (1969) fitted exponential relations to their observations of left ventricular pressure and volume under control conditions in a radiographic study in conscious dogs with intramyocardial metal markers. Administration of isoprenaline or methoxamine led to a greater increase in pressure in late diastole than that predicted from their exponential relation, which they ascribed to viscous effects. Comparison with our results is difficult since the connexion between pressure-volume relations and those between stress and strain is only indirect, but nevertheless it seems that a pronounced reduction in late diastolic distensibility may be observed under a wide variety of conditions.

Ventricular stiffness in late diastole has been studied by a number of workers. Bristow, Van Zee, and Judkins (1970) in a group of patients with coronary artery disease reported reduced compliance, defined as the ratio of the rate of change of volume to that of pressure in the last $0.2 \mathrm{sec}$ of diastole. Grossman et al. (1973) also found increased wall stiffness, defined as the ratio of the change in pressure to that in volume during atrial systole in patients with cardiographic evidence of left ventricular hypertrophy. Gaasch et al. (1972) reported increased wall stiffness in patients with cardiographic evidence of left ventricular hypertrophy due to valvular heart disease or cardiomyopathy. The properties of the left ventricle throughout diastole were assessed by Dodge, Hay, and Sandler (1962) using angiographic measurements of ventricular volume made over 3 to 4 cardiac cycles. These workers demonstrated a break in the pressure-volume curve towards the end of diastole, when wall stiffness suddenly increased. In addition, the early portion of the curve demonstrated a period when ventricular volume began to increase while pressure was still falling. Our results, therefore, are comparable with these, and with more recent studies (Altieri, Wilt, and Leighton, 1973; McLaurin, Rolett, and Grossman, 1973) and show, in addition, that the increase in wall stiffness in late diastole is 
not dependent on changes in cavity size or filling pattern, but reflects differences in the structure of the wall associated with the presence or absence of cardiographic evidence of left ventricular hypertrophy.

The present study may have implications for the measurement of ventricular stiffness in the clinical setting, since it indicates that no simple relation exists between wall stress and strain in the beating heart, and that the diastolic properties of the ventricle are modified by the previous systole. They are not comparable, therefore, with results based on assumed exponential relations between pressure and volume (Diamond and Forrester, 1971) or stress and strain (Mirsky and Parmley, 1973) derived from postmortem specimens. Secondly, in view of the nature of the stress-strain relation, a realistic assessment of it cannot be made from pairs of observations in early and late diastole. These do not take account of the changes occurring during the filling period, and so may give results in no way related to the properties of the myocardium itself. The present observations are subject to the limitation that they only apply to a localized region of the left ventricular cavity. Nevertheless, this information is available with minimal geometrical assumptions, and requires only Io to 15 minutes to collect with a similar period to process. This approach, therefore, has the potential of making measurements of the properties of the ventricular wall throughout diastole available for routine assessment of patients.

\section{References}

Altieri, P. I., Wilt, S. M., and Leighton, R. F. (I973). Left ventricular wall motion during the isovolumic relaxation period. Circulation, 48, 499.

Brecher, G. A. (1958). Critical review of recent work on ventricular diastolic suction. Circulation Research, 6, 554 .

Bristow, J. D., van Zee, B. E., and Judkins, M. P. (1970). Systolic and diastolic abnormalities of the left ventricle in coronary artery disease. Studies in patients with little or no enlargement of ventricular volume. Circulation, 42, 219.

Diamond, G., and Forrester, J. S. (1972). Effects of coronary artery disease and acute myocardial infarction on left ventricular compliance in man. Circulation, 45, II.

Dodge, H. T., Hay, R. E., and Sandler, H. (I962). Pressurevolume characteristics of the diastolic left ventricle of man with heart disease. American Heart fournal, 64, 503 .

Dodge, H. T., Sandler, H., Baxley, W. A., and Hawley, R. R. (1966). Usefulness and limitations of radiographic methods for determining left ventricular volume. American fournal of Cardiology, 18, 10.

Eber, L. M., Greenberg, H. M., Cooke, J. M., and Gorlin, R. (1969). Dynamic changes in left ventricular free wall thickness in the human heart. Circulation, 39, 455.

Falsetti, H. L., Mates, R. E., Grant, C., Greene, D. G., and
Bunnell, I. L. (1970). Left ventricular wall stress calculated from one-plane cineangiography. Circulation $\mathrm{Re}$ search, 26, 71.

Gaasch, W. H., Battle, W. E., Oboler, A. A., Banas, J. S., Jr., and Levine, H. J. (1972). Left ventricular stress and compliance in man: with special reference to normalized ventricular function curves. Circulation, 45, 746.

Gay, W. A., and Johnson, E. A. (1967). An anatomical evaluation of the myocardial length-tension diagram. Circulation Research, 21, 33.

Gibson, D. G. (1973). Estimation of left ventricular size by echocardiography. British Heart fournal, 35, 128.

Gibson, D. G., and Brown, D. (1973). Measurement of instantaneous left ventricular dimension and filling rate in man, using echocardiography. British Heart fournal, 35, II4I.

Gibson, D. G., and Brown, D. J. (1974). Use of echocardiography in the evaluation of left ventricular function. Proceedings of the Royal Society of Medicine, 67, 140 .

Grimm, A. F., Katele, K. V., Kubota, R., and Whitehorn, W. V. (1970). Relation of sarcomere length and muscle length in resting myocardium. American fournal of Physiology, 218, 1412.

Grossman, W., Stefadouras, M. A., McLaurin, L. P., Rolett, E. L., and Young, D. T. (1973). Quantitative assessment of left ventricular diastolic stiffness in man. Circulation, 47, 567 .

Hefner, L. L., Sheffield, L. T., Cobbs, G. C., and Klip, W. (I962). Relation between mural force and pressure in the left ventricle of the dog. Circulation Research, 11, 654 .

Horwitz, L. D., and Bishop, V. S. (1972). Left ventricular pressure-dimension relationships in the conscious dog. Cardiovascular Research, 6, 163.

McLaurin, L. P., Rolett, E. L., and Grossman, W. (1973). Incomplete ventricular relaxation and diastolic compliance (abstract). American fournal of Cardiology, 31, 146.

Millar, H. D., and Baker, L. E. (1973). A stable ultraminiature catheter-tip pressure transducer. Medical and Biological Engineering, 11, 86.

Mirsky, I., and Parmley, W. W. (1973). Assessment of passive elastic stiffness for isolated heart muscle and the intact heart. Circulation Research, 33, 233.

Noble, M. I. M., Milne, E. N. C., Goerke, R. J., Carlsson, E., Domenech, R. J., Saunders, K. B., and Hoffman, J. I. E. (1969). Left ventricular filling and diastolic pressurevolume relations in the conscious dog. Circulation $R e$ search, 24, 269.

Oram, S. (197I). Clinical Heart Disease, p. I71. Heinemann, London.

Sjögren, A. L., Hytönen, I., and Frick, M. H. (1970). Ultrasonic measurements of left ventricular wall thickness. Chest, 57, 37.

Troy, B. L., Pombo, J., and Rackley, C. E. (1972). Measurement of left ventricular wall thickness and mass by echocardiography. Circulation, 45, 602.

Tallarida, R. J., Rusy, B. F., and Loughnane, M. H. (1970). Left ventricular wall acceleration and the law of Laplace. Cardiovascular Research, 4, 217.

Requests for reprints to Dr. D. G. Gibson, Cardiac Department, Brompton Hospital, Fulham Road, London $\mathrm{SW}_{3} 6 \mathrm{HP}$. 